DOI 10.1590/1807-01912014202291

\title{
Terrorismo e Estados Falidos: uma análise de discurso crítica
}

\begin{tabular}{c}
\hline \hline Aureo de Toledo Gomes \\
Instituto de Economia \\
Universidade Federal de Uberlândia \\
Rossana Rocha Reis \\
Departamento de Ciência Política \\
Universidade de São Paulo \\
Tainah Espíndola \\
Graduada em Relações Internacionais \\
Universidade Federal de Uberlândia \\
\hline \hline
\end{tabular}

\begin{abstract}
Resumo: Mediante aportes conceituais da Análise de Discurso Crítica de Norman Fairclough, o artigo analisa a política externa norte-americana durante o governo George W. Bush (2001-2008). De forma mais precisa, a partir da leitura de documentos oficiais selecionados, objetiva-se averiguar a construção discursiva das ameaças aos EUA, com ênfase em três pontos: a construção de identidades em torno do terrorismo transnacional e dos chamados Estados Falidos; a recepção e a reprodução do discurso e como estes sentidos influenciariam a ação política norte-americana; e como tais elementos contribuem para justificar a atuação internacional dos EUA. Ademais, em termos teóricos e metodológicos, espera-se contribuir ao demonstrar os potenciais da Análise de Discurso Crítica para o estudo das Relações Internacionais.
\end{abstract}

Palavras-chave: terrorismo; estados falidos; política externa dos EUA; democracia; análise de discurso crítica

Abstract: Using Norman Fairclough's Critical Discourse Analysis, this article aims at analyzing U.S. foreign policy under George W. Bush (2001-2008). Therefore, after the reading of official documents, we intend to study the discursive construction of new threats against the United States, with particular focus on three issues: first, the construction of identities around transnational terrorism and the so-called failed states; secondly, the reception and reproduction of this discourse and how these specific meanings affected U.S. political action; and how these elements are connected to the strategies of U.S foreign policy in the postCold War era. Finally, concerning theoretical and methodological issues, we expect to underline the potential of Critical Discourse Analysis to the study of International Relations.

Keywords: terrorism; failed states; U.S. foreign policy; democracy; critical discourse analysis 


\section{OPINIÃO PÚBLICA, Campinas, vol. 20, no 2, agosto, 2014, p. 291-310}

Introdução ${ }^{1}$

Na área de Relações Internacionais ${ }^{2}$ já é quase senso comum destacar o impacto dos atentados terroristas de 11 de setembro de 2001 para os EUA e as consequências daí decorrentes. Frente a tal conjuntura, a resposta do governo norte-americano, então capitaneado pelo republicano George W. Bush (2001-2008), pautou-se pelo que se convencionou chamar Doutrina Bush, a qual, em linhas bastante gerais, propugnava uma postura externa ofensiva, recorrendo ao uso da força de forma preventiva para neutralizar quaisquer ameaças, presentes ou futuras. Nesse sentido, as principais traduções políticomilitares daquilo que viria a ser conhecido como Guerra ao Terror foram as intervenções no Afeganistão em outubro de 2001, cujo governo era considerado cúmplice de Osama Bin Laden, e no Iraque em março de 2003, a partir de alegadas - mas nunca comprovadas - provas da produção de armas de destruição em massa pelo regime de Saddam Hussein, assim como de suas ligações com a Al Qaeda.

Após uma década dos ataques e a sucessão do republicano Bush pelo democrata Barack Obama, tornou-se tarefa quase impossível catalogar as obras em Relações Internacionais que, de uma forma ou de outra, avaliam o impacto do evento para os EUA ${ }^{3}$. Não obstante, se nos atentarmos para o contexto norte-americano após os atentados, um dos traços que logo salta aos olhos é a proliferação de novos termos, e o uso de outros que até então estavam esquecidos, para significar ações e fenômenos sociais. Dito de outra forma, expressões como Guerra ao Terror, Estados Falidos ${ }^{4}$, Mudança de Regime, dentre outras, passam a povoar o imaginário norte-americano e internacional, imprimindo sentido e orientando a política externa dos EUA. Aqueles interessados na compreensão da construção de identidades e sentidos, na maioria das vezes, optaram por análises discursivas que, retomando Foucault (2008), buscam compreender as condições de existência de dado enunciado, mostrar porque ele não poderia ser diferente do que ele é. Em outras palavras, como determinada decisão política se tornou concebível? Quais são as condições que permitem a emergência da Guerra ao Terror e dos Estados Falidos como ameaças à segurança internacional? Quais os impactos dessa constelação de sentidos para as relações internacionais e para a ação externa dos EUA? A despeito de serem indagações em nosso entender nada desprezíveis, infelizmente ainda são poucas as obras que procuram compreender a construção desses sentidos e como, por exemplo, os mesmos foram utilizados para normalizar e reificar práticas contraterroristas ${ }^{5}$.

O objetivo deste artigo é, portanto, realizar uma dupla intervenção no debate. Em primeiro lugar, ao realizar uma análise discursiva sobre os sentidos criados e reproduzidos após atentados de 11

\footnotetext{
1 Agradecemos os valiosos comentários e sugestões do parecerista anônimo de Opinião Pública. Eventuais imprecisões que porventura ainda persistam no artigo são de nossa única e exclusiva responsabilidade.

2 Quando em maiúsculas, Relações Internacionais refere-se ao campo do conhecimento. Por outro lado, quando em letras minúsculas, a expressão relações internacionais faz referência ao objeto de estudo.

3 A partir de distintas matrizes teóricas e metodológicas, além do recorte dado ao objeto de estudo, são bastante diversas as obras que procuram avaliar o impacto do 11 de setembro de 2001 para a política externa norte-americana. Para uma visão geral do impacto dos atentados, sugerimos Daalder e Lindsay (2004); sobre o peso do pensamento neoconservador no governo George W. Bush, remetemos os interessados a Monten (2005) e Teixeira (2007); e, por fim, para uma discussão sobre a gravidade do terrorismo e dos Estados considerados Párias e Falidos para a segurança internacional e dos EUA, destacamos Litwak (2000; 2007) e Pillar (2003).

4 Apesar dos documentos oficiais dos EUA não usarem a expressão Estados Falidos, substituindo-a por termos como Estados fracos ou frágeis, no decorrer deste artigo faremos uso do primeiro termo, dado ser ele consagrado na literatura especializada. Para uma revisão sobre o tema, sugerimos Monteiro (2006).

5 No exterior, as obras de Jackson (2005), Jarvis (2009), Nabers (2009) e Hodges (2011) são tentativas louváveis de se compreender como a construção de sentidos em torno da Guerra ao Terror contribuiu para normalizar as ações políticas norte. americanas após os atentados. No Brasil, os trabalhos de Castro Santos (2010), Mendes (2008), Resende (2012) e Gomes (2012), salvo melhor juízo, são as únicas análises discursivas aplicadas para temáticas que envolvem terrorismo e política externa norte-americana; Vilela e Neiva (2011), por sua vez, fazem uma interessante Análise de Conteúdo aplicada à política externa brasileira, comparando os discursos dos ex-presidentes Luiz Inácio Lula da Silva e Fernando Henrique Cardoso.
} 
GOMES, A. T.; REIS, R. R.; ESPÍNDOLA, T. Terrorismo e Estados Falidos:...

de setembro de 2001, pretendemos intervir no debate acadêmico demonstrando a importância das representações para o estudo da política internacional, assim como o potencial da análise do discurso para a área de Relações Internacionais. Delimitando o objeto de estudo, nosso intento é compreender, a partir da análise de documentos oficiais do governo George W. Bush, a construção das identidades em torno do terrorismo transnacional e dos chamados Estados Falidos, destacando como estes últimos seriam vistos como causas da proliferação de grupos terroristas, além de apresentarmos o que entendemos como os principais impactos dessa constelação de sentidos para a ação política dos EUA. Mediante a leitura dos documentos, o problema de pesquisa que pretendemos abordar é que a caracterização das causas do terrorismo como fragilidades institucionais dos Estados Falidos culmina em uma visão da intervenção externa enquanto tarefa técnica, na medida em que agora as operações são vistas como fortalecendo os países em tela, e não como formas de ingerência em busca de interesses diversos. Tal concepção, em nosso entender, seria uma forma de se justificar as ações da política externa norte-americana depois dos atentados de 11 de setembro, mas que está conectada com a discussão ideológica e política presente nos EUA desde o final da Guerra Fria, especialmente o papel da exportação democrática para a política externa do país.

Para tanto, a investigação da conexão entre discurso e construção da realidade se torna possível mediante o aporte conceitual da Análise de Discurso Crítica, principalmente mediante os trabalhos do linguista britânico Norman Fairclough (2001; 2003), os quais compõem o que se convencionou chamar Teoria Social do Discurso ${ }^{6}$.

Em segundo lugar, nosso esforço pode ser compreendido também como uma intervenção de ordem política, na medida em que procuramos questionar representações que correntemente vêm sendo naturalizadas e muitas vezes compreendidas como verdadeiros axiomas nas abordagens tradicionais de Relações Internacionais, mostrando que se tratam de criações sociais, influenciadas por atores e conjunturas históricas específicas.

Para tanto, o artigo está dividido em três seções, excetuando-se esta introdução. Primeiramente, apresentamos o arcabouço teórico-metodológico proposto por Nornam Fairclough e como o mesmo informa a análise. No segundo momento, efetuamos a análise propriamente dita, com destaque especial para três pontos específicos: as identidades criadas e associadas ao terrorismo e aos chamados Estados Falidos, a produção e a recepção do discurso e seus impactos na ação política dos EUA, e, por fim, como o discurso em tela contribui para manutenção da postura ofensiva da política externa norte-americana. Finalmente, as considerações finais sintetizam brevemente os resultados encontrados, destacando o potencial de trabalhos informados pela Análise de Discurso Crítica para a área de Relações Internacionais.

\footnotetext{
${ }^{6}$ Da lista de trabalhos arrolados na nota de rodapé anterior, Jackson (2005) e Hodges (2011) fazem uso dos aportes conceituais de Fairclough para a análise. No Brasil, até o momento, não encontramos nenhum trabalho que utilize as ideias do autor para analisar terrorismo ou política externa norte-americana: os únicos trabalhos encontrados são as obras de Ramalho (2005), sobre o discurso da imprensa brasileira sobre a intervenção dos EUA no Iraque, e Santos Netto (2011), que investiga a construção do nacionalismo hispano-americano mediante a análise de documentos de Símon Bolivar. Contudo, é importante destacar que na área de Linguística no Brasil, temos trabalhos consolidados informados pela Análise de Discurso Crítica, em especial aqueles realizados por Izabel Magalhães, Denize Elena Garcia da Silva, Viviane Ramalho e Viviane Resende, professoras do Instituto de Letras da UnB. O volume 21 de 2005 da revista D.E.L.T.A., publicação da PUC.SP, é um bom exemplo da qualidade da produção nacional informada pela Análise de Discurso Crítica.
} 
OPINIÃO PÚBLICA, Campinas, vol. 20, no 2, agosto, 2014, p. 291-310

\section{A Análise de Discurso Crítica}

A Análise de Discurso Crítica (Critical Discourse Analysis) enquanto rede de pesquisadores e proposta teórico-metodológica tem como marco fundacional a realização de um simpósio científico em janeiro de 1991 em Amsterdã, ocasião esta em que Gunther Kress, Norman Faiclough, Ruth Wodak, Teun van Dijk e Theo van Leewen se reuniram durante dois dias para discutir e confrontar suas perspectivas sobre análise do discurso e suas agendas de pesquisa (WODAK, 2001). A partir desse contato, ainda que a despeito das diferenças epistemológicas entre os autores, uma rede de pesquisas começou a se consolidar, e se fortaleceu ainda mais com as obras posteriores dos pesquisadores e também com o surgimento de periódicos específicos na área, tais como o Critical Discourse Studies ${ }^{7}$.

Dentre os principais nomes da Análise de Discurso Crítica, certamente se destaca o linguista britânico Norman Fairclough, professor Emérito da Universidade de Lancaster. Conforme Magalhães (2005), a contribuição intelectual de Fairclough é reconhecida por dois motivos principais: primeiramente, a partir de sua concepção original sobre discurso, o autor deixou claro para cientistas sociais e estudiosos da mídia o quanto eles precisam dos linguistas para análises sociais; e, em segundo lugar, o autor proporcionou aos analistas um quadro metodológico que os permitisse investigar a relação entre discurso e mudança social. Explicitar estes dois pontos é um bom ponto de partida para destacarmos a relevância de suas ideias para os propósitos deste artigo.

Desde o final da década de 1980, Fairclough envida esforços para a consolidação de uma abordagem teórica e metodológica que destaque a importância da análise linguística para a compreensão das mudanças sociais. O porquê dessa tarefa se deve ao fato de que para Fairclough $(2001)^{8}$ a linguagem e outros elementos semióticos, tais como imagens, por exemplo, são parte da vida social e estão dialeticamente conectadas às outras esferas da vida, tais como práticas relativas ao mundo do trabalho, da educação, dentre outras. A orientação do autor, portanto, rompe com a visão da linguagem enquanto mero reflexo de condições materiais existentes na sociedade e como atividade puramente individual, propondo assim uma concepção de discurso como forma de prática social. Em suma, a linguagem e outros elementos semióticos devem ser entendidos enquanto processo e produto social.

Tal orientação teórica apresenta implicações importantes que precisam ser mais bem esmiuçadas. Primeiramente, o discurso passa a ser entendido como um modo de ação, isto é, uma forma das pessoas agirem sobre a realidade e sobre outros indivíduos, além de ser um instrumento para a representação do real. Em segundo lugar, temos uma relação dialética entre discurso e realidade: ao mesmo tempo em que o discurso enquanto prática social é moldado e constrangido pela estrutura social mediante relações de classe, relações em instituições sociais específicas, como o direito e a educação, dentre outras, de outro lado, o discurso contribui para a construção de todas as dimensões da estrutura social, na medida em que é por meio dele que se criam significados e sentidos que irão orientar a ação dos atores. Para demonstrar seu argumento, e influenciado pelo diálogo travado com a Linguística Sistêmica Funcional, especialmente os trabalhos de Halliday, Fairclough (2001) aponta três funções de

\footnotetext{
7 Para maiores detalhes sobre as origens da Análise de Discurso Crítica, remetemos os interessados a Wodak (2001) e Resende e Ramalho (2006).

${ }^{8}$ Para a redação do artigo, apesar de utilizarmos a edição brasileira do livro Discurso e Mudança Social, é importante destacar que a primeira edição em inglês do livro foi publicada em 1992. Cronologicamente, as principais ideias de Fairclough foram desenvolvidas nos livro de 1992, na obra Discourse in Late Modernity (Chouliaraki; FaIRCLOUGH,1999) e no livro Analysing Discourse (FAIRCLOUGH, 2003).
} 
GOMES, A. T.; REIS, R. R.; ESPÍNDOLA, T. Terrorismo e Estados Falidos:...

linguagem, quais sejam, a identitária, a relacional e a ideacional como as maneiras por meio das quais o discurso exerce seu caráter construtivo: a primeira refere-se às formas pelas quais as identidades sociais são estabelecidas no discurso, a segunda diz respeito a como as relações sociais entre os participantes do discurso são representadas, enquanto a terceira faz referência ao modo pelo qual o discurso significa o mundo, contribuindo para a construção de sistemas de conhecimento e crenças.

Por conseguinte, para Fairclough (2001), o discurso deve ser compreendido como uma forma de ação historicamente situada, visto que estruturas organizam a produção discursiva nas sociedades, porém, cada novo enunciado é uma ação individual sobre tais estruturas, que podem tanto objetivar a manutenção do status quo como a transformação social. Aproveitando o gancho, o caráter crítico da abordagem do autor está sumamente relacionado com a ideia de que a análise deve contribuir para a ruptura de relações de dominação e a busca pela emancipação social, visto que o discurso enquanto prática política estabelece relações de poder e entidades coletivas, sejam elas classes, blocos, comunidades, entre outras, ao passo que o discurso como prática ideológica constitui, naturaliza, mantém, ou mesmo transforma os significados do mundo daqueles inseridos nessas relações de poder ${ }^{9}$. Em outras palavras, parte-se da premissa de que situações opressoras podem ser mudadas por serem criações sociais, e de que a linguagem é o palco privilegiado para a transformação, na medida em que nessa esfera se travam importantes disputas para se estruturar hegemonias, (re)construir identidades e se veicular ideologias.

Uma vez delineada, ainda que brevemente, a concepção de discurso de Fairclough, trata-se agora de apresentar a forma como o autor operacionaliza sua orientação teórica. O quadro tridimensional para análise do discurso é a primeira contribuição metodológica do autor, estruturado conforme a Figura 1:

\footnotetext{
9 Para ilustrar este ponto, dois exemplos são interessantes. Tomando como referência a ideia de Rajagopalan (2003) de que o processo de nomeação é um ato de caráter profundamente político, pois, dependendo da forma como é levada a cabo, a nomeação pode ter consequências distintas, na medida em que a construção de identidades e significados começa a partir da designação, dizer "presidente Hugo Chavez" ou "caudilho Hugo Chavez", por exemplo, é um ato político, visto que implica um posicionamento ante o evento, visto que se está tomando partido de determinada posição ideológica a partir do próprio ato da nomeação. Outro exemplo é trazido por Resende (2005) em seu estudo sobre a infância nas ruas. Segundo a autora, termos como "sem-teto" e "meninos de rua" seriam formas de se naturalizar o estado dessas pessoas como condição permanente, isto é, elas não estão sem teto, são sem-teto; não estão na rua, são da rua. Seria, portanto, uma forma de não se questionar a causa desse problema, tratando-os como características permanentes da sociedade.
} 
Figura 1

Modelo tridimensional para Análise de Discurso Crítica

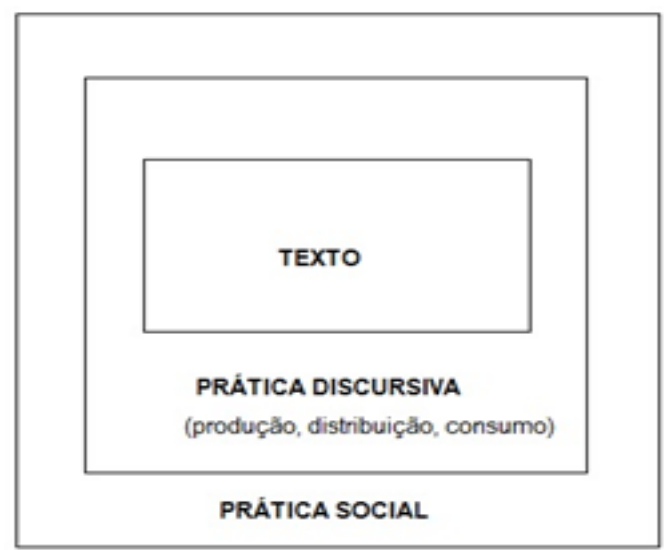

Fonte: Figura construída pelos autores a partir de Fairclough (2001).

Assim sendo, teríamos três dimensões passíveis de análise a partir do modelo proposto pelo autor. A análise do texto consiste na investigação das características formais dos documentos: trata-se de verificar o vocabulário, a gramática das palavras combinadas em orações e frases, a coesão entre orações e frases, e a estrutura organizacional, isto é, as propriedades organizacionais de larga escala do texto. Em outras palavras, a partir de ferramentas comuns na Linguística, a proposta é verificar como o texto constrói sujeitos e relações de poder, imputando significados aos fenômenos sociais. A prática discursiva faz referência a processos sociocognitivos de produção, distribuição e consumo do texto. Dito de outra forma, nesta etapa o questionamento é endereçado para questões relativas ao contexto no qual o texto foi produzido, qual o público-alvo e que impactos ele teve na sociedade. Por fim, à análise da prática social interessa averiguar como o discurso contribui para a manutenção ou transformação do status quo, verificando como ele mantém ou transforma ideologias. De todas as etapas da análise, Fairclough (2001) considera esta a mais difícil de ser reduzida a uma lista e, portanto, o analista deve realizá-la tendo em mente as características de seu objeto de estudo.

É importante destacar a complementaridade entre as obras que compõem a Teoria Social do Discurso de Fairclough. O quadro ora apresentado é a primeira tentativa do autor de confrontar a temática da mudança social com aportes da Linguística. Todavia, na obra de 1999, na qual dialogam com autores da teoria social como Anthony Giddens, Pierre Bourdieu e David Harvey, Chouliaraki e Fairclough argumentam que, a despeito da inclinação natural da Linguística em torno da linguagem e do semiótico, esta centralização poderia acarretar problemas para uma teoria cuja pretensão é demonstrar a relação dialética entre discurso e realidade. Por conseguinte, os autores realizam alterações no modelo metodológico, passando a enfatizar a dimensão da prática social ${ }^{10}$.

\footnotetext{
10 O novo modelo consiste em cinco etapas. Primeiramente, temos a percepção do problema, que consiste na identificação da problemática calcada em relações de poder desiguais. Em segundo lugar, há a identificação dos obstáculos a serem superados, isto é, a identificação dos obstáculos existentes na prática social que sustentam o problema em tela. Em terceiro lugar, temos a verificação da função do problema na prática, ou seja, qual o papel do texto na prática discursiva e social. Em quarto lugar, ao explorar as possibilidades de mudança, o analista deve tentar superar os problemas encontrados inicialmente. Por fim, a última etapa consiste na reflexão sobre a própria análise, evidenciando que toda investigação deve ser autorreflexiva. Ademais, a partir de um diálogo bastante profícuo com a Linguística Sistêmica Funcional de Halliday, Fairclough (2003), dentre outros pontos, substitui a expressão funções de linguagem por tipos de significados. Assim, teríamos agora o significado acional, o qual entende o texto como um modo de interação entre eventos sociais; o significado representacional, que enfatiza a representação de
} 
GOMES, A. T.; REIS, R. R.; ESPÍNDOLA, T. Terrorismo e Estados Falidos:...

Duas notas de ordem metodológica precisam ser expostas antes de prosseguirmos. Em primeiro lugar, Fairclough (2001) afirma que há maneiras distintas de o analista do discurso confrontar seu objeto de estudo e que, portanto, seu modelo deve ser compreendido não como um esquema rígido, mas sim como diretrizes gerais que expressam os principais elementos e considerações que se aplicam à análise do discurso. Nessa toada, a ideia do autor em dividir as dimensões é apresentar, a partir de sua perspectiva teórica, de que modo se dá o movimento dialético entre discurso e estrutura social. Ademais, o autor ainda afirma que a sequência da análise - se do texto à prática discursiva, e, enfim, à prática social, ou o inverso - é uma prerrogativa do analista, dependendo do propósito e da ênfase do trabalho.

Em segundo lugar, apesar de estarmos cientes das mudanças metodológicas realizadas pelo autor ao longo do tempo, optamos por utilizar o modelo tridimensional apresentado na Figura 1, devido aos propósitos específicos do artigo. Precisando o argumento, a partir da caracterização do terrorismo e dos Estados Falidos nos documentos oficiais produzidos durante o governo George W. Bush, pretendemos mostrar como estes significados impactaram a ação política norte-americana, ou seja, a ênfase recairá mais sobre como os sentidos produzidos influenciaram a política externa do país após os atentados. Para tanto, a análise vai do texto, passa pela prática discursiva, e, enfim, alcança a prática social.

Os documentos selecionados para a análise são as duas The National Security Strategy of the United States of America, de 2002 e 2006 (doravante, NSS.02 e NSS.06, respectivamente) e o documento Fragile States Strategy, de 2005, (doravante, FSS-05), produzido pela United States Agengy for International Development (USAID). Apesar de pequena, a amostra é, salvo melhor juízo, bastante representativa: a escolha desses documentos se justifica na medida em que apresentam as principais caracterizações sobre Estados Falidos e terrorismo, e podemos afirmar, dado que são os únicos documentos oficiais do governo dos EUA sobre o tema, os significados aí encontrados foram posteriormente reproduzidos nas demais instâncias do governo norte-americano, especialmente aquelas cujas funções estavam relacionadas com temas de defesa e segurança nacional. Finalmente, amparados teórica e metodologicamente pelas ideias do autor, podemos iniciar a análise propriamente dita.

\section{Análise de Discurso Crítica e a Política Externa dos EUA}

Seguindo as orientações teórico-metodológicas do modelo tridimensional de Fairclough e aplicando-as para o objeto de estudo em questão, a análise da política externa dos EUA demanda a realização de três movimentos: primeiramente, a análise textual, para a verificação da construção de sentidos em torno do terrorismo e dos ditos Estados Falidos; a repercussão desses significados dentro do governo; e, por fim, como tais significações estão conectadas com as ideologias e os interesses mais amplos da política externa norte-americana. Assim, vejamos:

aspectos do mundo em textos; e, por fim, o significado identificacional, que se refere à construção e negociação de identidades no discurso. Para uma visão sobre a evolução do pensamento de Fairclough, o melhor trabalho é o de Resende e Ramalho (2006). 
OPINIÃO PÚBLICA, Campinas, vol. 20, no 2, agosto, 2014, p. 291-310

\section{Análise textual}

Para analisar a construção de significados nas NSS.02 e NSS.06, um expediente bastante interessante é o que Lynn-Doty (1993) chama de predicação e pressuposição: enquanto a primeira análise consiste na verificação da atribuição de qualidades e propriedades aos objetos em questão mediante adjetivos e advérbios, a segunda busca capturar os pressupostos que criariam as condições para o conhecimento de base. Dito de outra forma, quando se afirma, por exemplo, que a lógica da política de poder é relevante, pois captura a essência do sistema internacional, temos que há algo conhecido como política de poder e que o sistema internacional possui uma essência passível de ser descortinada pelo analista.

Prosseguindo, a NSS.02 e a NSS.06 são documentos fundamentais, uma vez que irão ditar os termos do debate sobre o terrorismo dentro do governo. Publicada em setembro de 2002, a NSS.02, um documento com 13.069 palavras, sendo que desse montante 2.341 são palavras diferentes uma das outras $^{11}$, apresenta ao público as principais características do sistema internacional contemporâneo, salientando a natureza das principais ameaças. Nesse sentido, uma primeira caracterização sobre o terrorismo surge logo na página inicial, a partir de um contraste com os inimigos do passado:

"Defending our Nation against its enemies is the first and fundamental commitment of the Federal Government. Today, that task has changed dramatically. Enemies in the past needed great armies and great industrial capabilities to endanger America. Now, shadowy networks of individuals can bring great chaos and suffering to our shores for less than it costs to purchase a single tank. Terrorists are organized to penetrate open societies and to turn the power of modern technologies against us" (Nss-02, p. iv, grifos nossos) ${ }^{12}$.

A partir do trecho, é possível compreender que existe uma nova ameaça, diferente daquelas do passado, e que demanda novas formas de ação. Contudo, inobstante o perigo do terrorismo, o próprio documento reconhece que o desempenho desses grupos depende da capacidade de penetração dos mesmos em outros países, os quais proveriam as condições materiais para o planejamento e a atuação das redes terroristas. A partir daí, temos as primeiras caracterizações dos Estados ditos Párias e Falidos. Os dois trechos abaixo são ilustrativos da atribuição de sentidos que a NSS-02 oferece:

"In the 1990s we witness the emergence of a small number of rogue states that, while different in important ways, share a number of attributes. These states:

- $\quad$ brutalize their own people and squander their national resources for the personal gain of the rules;

- display no regard for international law, threaten their neighbors, and callously violate international treaties to which they are party;

\footnotetext{
${ }^{11}$ A obtenção dos números foi realizada mediante o processamento dos documentos aqui selecionados no software Wordsmith 3.1, bastante conhecido e utilizado em trabalhos no ramo da Linguística conhecido como Linguística de Corpus, que, grosso modo, ocupa-se da coleta e da exploração de dados linguísticos textuais a partir do uso de software. Ademais, a Linguística de Corpus procura fazer inferências sobre a linguagem mediante um volume significativo de dados linguísticos. Neste artigo, o uso do software é bastante restrito, mobilizado simplesmente para precisar o tamanho do corpus. Para maiores detalhes sobre a Linguística de Corpus e o funcionamento do software, sugerimos o trabalho de Berber Sardinha (2004).

12 Todos os trechos extraídos do corpus serão mantidos no original em inglês, para que os leitores possam comparar nossas conclusões com a versão original dos documentos.
} 


\section{GOMES, A. T.; REIS, R. R.; ESPÍNDOLA, T. Terrorismo e Estados Falidos:...}

- $\quad$ are determined to acquire weapons of mass destruction, along with other advanced military technology, to be used as threats or offensively to achieve the aggressive designs of these regimes;

- $\quad$ sponsor terrorism around the globe; and

- $\quad$ reject the basic human values and hate the United States and everything for which it stands" (Nss-02, p.p. 13-14, grifos nossos).

"The events of September 11, 2001, taught us that weak states, like Afghanistan, can pose as great a danger to our national interests as strong states. Poverty does not make poor people into terrorists and murderers. Yet poverty, weak institutions, and corruption can make weak states vulnerable to terrorist networks and drug cartels within their borders" (Nss-02, p. v, grifos nossos).

Note-se a diferença. Para os Párias internacionais, o documento dispensa uma caracterização comportamental como traço definidor: em outras palavras, são países que apresentam uma conduta desviante e, portanto, são uma ameaça iminente aos EUA e ao sistema internacional como um todo. Não à toa, a construção de sentidos para tais países está sumamente ancorada em verbos de ação, ou seja, deliberadamente tais Estados planejam praticar atos contra todo o sistema. Por outro lado, aos ditos Estados Falidos, a construção de sentidos repousa sobre a ausência de determinados predicados que seriam considerados essenciais para se evitar a proliferação do terrorismo em seus domínios. Assim sendo, a caracterização do fracasso estatal passa pela atribuição de adjetivos e substantivos a tais países, como fraqueza, corrupção, instituições fracas, dentre outros. Em suma, estes países são uma ameaça não por vontade própria, mas por carências estruturais - sejam elas causadas pela história ou mesmo por lideranças inaptas -, as quais os impedem de desempenharem as responsabilidades soberanas de qualquer Estado.

Consequentemente, as construções de sentido apresentadas fundamentam e justificam a postura norte-americana no contexto pós-11 de setembro. Para o caso dos Párias, a resposta é clara e objetiva: frente a tal perigo, os EUA devem agir de forma preventiva e assertiva, ainda que tais ameaças não estejam concretizadas:

"The greater the threat, the greater is the risk of inaction - and the more compelling the case for taking anticipatory action to defend ourselves, even if uncertainty remains as to the time and place of the enemy's attack. To forestall or prevent such hostile acts by our adversaries, the United States will, if necessary, act preemptively" (Nss-02, p. 15, grifos nossos).

Em contraposição, para o caso dos Estados Falidos, a resposta é outra, dada a diferença da natureza atribuída ao problema, e consiste, basicamente, no auxílio à construção das instituições essenciais de qualquer país. O seguinte trecho ilustra o ponto:

“Together with our European allies, we must help strengthen Africa's fragile states, help build indigenous capability to secure porous borders, and help build up the law enforcement and intelligence infrastructure to deny havens for terrorists" (Nss-02, p.p. 10. 11, grifos nossos). 
A partir da análise da NSS-02, mapeamos os termos EUA, terrorismo, Estados Pária e Estados Falidos e elaboramos a Tabela 1, cujo objetivo principal é mostrar a frequência com que os termos aparecem e quais são as principais associações. Com isso, esperamos prover mais subsídios para as ideias até aqui avançadas.

\section{Tabela 1}

\begin{tabular}{|l|c|l|}
\hline Expressões & Frequência & Principais associações \\
\hline Inimigo(s) & 19 & $\begin{array}{l}\text { ameaça; armas de destruição em massa; devem ser derrotados; falta de } \\
\text { valores morais; inimigos da civilização; aliados do terror }\end{array}$ \\
\hline $\begin{array}{l}\text { Terror/ } \\
\text { Terrorismo/Terrorista(s) }\end{array}$ & 90 & $\begin{array}{l}\text { guerra contra o terrorismo; perigo contra inocentes; perigo global; } \\
\text { impedir seu acesso a armas de destruição em massa; devem ser } \\
\text { destruídos }\end{array}$ \\
\hline $\begin{array}{l}\text { Estados Párias/Regimes } \\
\text { Párias }\end{array}$ & 10 & $\begin{array}{l}\text { necessidade de detê-los; prevenir; associados ao terrorismo; vão contra } \\
\text { a ordem internacional; armas de destruição em massa; comportamento } \\
\text { agressivo e pouco confiável; antidemocráticos }\end{array}$ \\
\hline $\begin{array}{l}\text { Estados Fracos/ Estados } \\
\text { frágeis }\end{array}$ & 3 & $\begin{array}{l}\text { representam perigo para a comunidade internacional; vulneráveis ao a } \\
\text { terrorismo; instituições fracas; pobreza }\end{array}$ \\
\hline Obrigação dos EUA & 65 & $\begin{array}{l}\text { deter o terrorismo; conter a proliferação de armas de destruição em } \\
\text { massa; fazer do mundo um lugar melhor; garantir a segurança dos EUA } \\
\text { e dos países aliados }\end{array}$ \\
\hline
\end{tabular}

Fonte: Autoria própria, a partir do processamento dos documentos selecionados no software Wordsmith 3.1.

A NSS-06, com suas 18.640 palavras, das quais 2.975 são diferentes entre si, é a revisão da estratégia apresentada no documento de 2002. Inobstante as poucas inovações em relação à NSS.02, este novo documento, ao enfatizar a relação de causalidade entre Estados Falidos e terrorismo, destaca a importância da democracia como solução para o problema da proliferação de grupos terroristas. Os trechos que seguem são significativos dessa atribuição de sentidos:

\footnotetext{
"Weak and impoverished states and ungoverned areas are not only a threat to their people and a burden on regional economies, but are also susceptible to exploitation by terrorists, tyrants, and international criminals. We will work to bolster threatened states, provide relief in times of crisis, and build capacity in developing states to increase their progress" (Nss. 06, p. 33, grifos nossos).

'Governments that honor their citizens' dignity and desire for freedom tend to uphold responsible conduct toward other nations, while governments that brutalize their people also threaten the peace and stability of other nations. Because democracies are the most responsible members of the international system, promoting democracy is the most effective long-term measure for strengthening international stability; reducing regional conflicts; countering terrorism and terror-supporting extremism; and extending peace and prosperity" (Nss-06, p. 3, grifos nossos).
}

Dado o poder catalisador da democracia para solucionar o problema dos Estados Falidos, cujas origens são, de acordo com a interpretação apresentada pelos documentos selecionados, sumamente domésticas e desconectadas das dinâmicas do próprio sistema internacional, esboça-se a caracterização de uma resposta técnica para o problema: não se trata de uma intervenção militar, e sim de ajuda direcionada com vistas a fortalecer as instituições dos países em questão e, por conseguinte, equipá-los para enfrentar os desafios do novo contexto internacional. Mediante a resposta dos EUA para os problemas africanos, podemos dar um exemplo de tal argumento: 
GOMES, A. T.; REIS, R. R.; ESPÍNDOLA, T. Terrorismo e Estados Falidos:...

"Overcoming the challenges Africa faces requires partnership, not paternalism. Our strategy is to promote economic development and the expansion of effective, democratic governance so that African states can take the lead in addressing African challenges. Through improved governance, reduced corruption, and market reforms, African nations can lift themselves toward a better future. We are committed to working with African nations to strengthen their domestic capabilities and the regional capacity of the AU to support post-conflict transformations, consolidate democratic transitions, and improve peacekeeping and disaster responses" (Nss-06, p.p. 37 - 38, grifos nossos).

Com vistas a mapear e dar mais exemplos das principais associações encontradas neste documento, construímos a Tabela 2:

\section{Tabela 2}

\begin{tabular}{|c|c|c|}
\hline Expressões & Frequência & Principais associações \\
\hline Inimigo(s) & 15 & prevenir as possíveis ameaças \\
\hline $\begin{array}{l}\text { Terror/ } \\
\text { Terrorismo/Terrorista(s) }\end{array}$ & 121 & $\begin{array}{l}\text { impedir o acesso a armas de destruição em massa; acabar com as redes } \\
\text { terroristas; coalizão contra o terror; crime transacional; ameaça global; } \\
\text { tiranias; guerra contra o terror }\end{array}$ \\
\hline $\begin{array}{l}\text { Estados Párias/Regimes } \\
\text { Párias }\end{array}$ & 7 & $\begin{array}{l}\text { ligação com o terrorismo; prevenir o acesso a armas de destruição em } \\
\text { massa }\end{array}$ \\
\hline $\begin{array}{l}\text { Fraqueza } \\
\text { Estatal/Fracasso } \\
\text { Estatal/ Estados fracos/ }\end{array}$ & 11 & $\begin{array}{l}\text { vulnerabilidade para instalações terroristas; sistema financeiro fraco; } \\
\text { representam perigo para a comunidade internacional e para as economias } \\
\text { mundiais; pobreza; vulnerabilidade; necessidade de democratização; } \\
\text { abrigo ao terrorismo }\end{array}$ \\
\hline $\begin{array}{l}\text { Obrigações } \\
\text { dos EUA }\end{array}$ & 90 & $\begin{array}{l}\text { criar instituições fortes capazes de deter o terrorismo; defender a } \\
\text { dignidade humana; defender o mundo do terrorismo; promover o } \\
\text { crescimento econômico global; promover a cooperação internacional }\end{array}$ \\
\hline
\end{tabular}

Fonte: Autoria própria, a partir do processamento dos documentos selecionados no software Wordsmith 3.1 .

Num esforço de sintetizar a análise textual ora apresentada, é possível afirmar que os Estados Falidos proporcionariam as condições para as operações das ações de redes terroristas, mas não por ação deliberada, como é o caso dos Párias internacionais, mas porque carecem das capacidades estruturais para evitar a penetração desses grupos em seu território. Ademais, a fragilidade de tais países é sumamente associada a causas domésticas, essencialmente à ausência de instituições democráticas e de uma economia orientada para mercado, e dissociada de qualquer relação com outros países, com o próprio sistema internacional e com as dinâmicas do capitalismo contemporâneo. Assim sendo, diferente do combate assertivo dado aos países que patrocinam o terrorismo, a política externa norte-americana para estes Estados fracos é em alguma medida filantrópica: a ideia é apoiá-los num processo de reconstrução para que alcancem, mediante reformas estruturais, a condição de Estados bem-sucedidos, condição esta já usufruída pelos EUA e pelos seus aliados.

Com tal construção de sentidos, vemos que as causas do terrorismo estão relacionadas com eventos que ocorrem fora dos EUA, devido sumamente às inabilidades domésticas dos países em tela. Conforme os documentos, tudo era novo e, infelizmente, os EUA não estavam preparados: nessa toada, um dos argumentos mais repetidos pelo então presidente George W. Bush era de que "a guerra começou no tempo e nos termos do inimigo, mas irá terminar na hora e da maneira que nós escolhermos" (BuSH, 2002, p.5). Todavia, compartilhando da opinião de Jackson (2005), tal significação permite, por exemplo, isentar as falhas da inteligência norte-americana em detectar que os perpetradores das ações 
adquiriram treinamento em aviação civil nos EUA, assim como esquecer que estas ações terroristas devem ser compreendidas à luz do histórico de relações conturbadas no Oriente Médio e Ásia Central.

Em última instância, a construção dos EUA enquanto vítima representaria as posteriores ações militares do país como atos de autodefesa e o tratamento dispensado aos suspeitos de terrorismo como apropriados, a despeito da utilização de práticas de tortura. É importante frisar, contudo, que não estamos transferindo responsabilidades e isentando determinados países de seus prováveis problemas institucionais: trata-se sim de ampliar o quadro e ver que as interpretações relativamente simples apresentadas pelos documentos ignoraram uma parte significativa do problema e absolvem o governo George W. Bush de quaisquer responsabilidades no que tange a capacidade de se evitar os ataques.

Cumprida esta primeira etapa, voltamos nossas atenções para o segundo momento da análise, que almeja avaliar o impacto dessa construção de sentidos.

\section{Prática Discursiva}

Diferentemente do discurso da Guerra ao Terror, que foi consumido não apenas pelo governo, mas também por parcela significativa da sociedade ${ }^{13}$, a associação entre Estados Falidos e terrorismo, uma parte menor dessa grande constelação de sentidos, teve um impacto mais circunscrito, dado o caráter técnico outorgado ao problema, e ao fato de que a audiência que consumiu este discurso ser restrita, composta principalmente por analistas políticos e pesquisadores. Assim sendo, a meta da presente seção é averiguar como esta relação foi reforçada e justificada, e quais seus principais impactos para a ação política dos EUA.

Para tanto, a análise da FSS-05, o documento que estabelece a estratégia norte-americana para Estados Falidos, tem em mente o que Fairclough (2001) chama de intertextualidade: trata-se, em linhas gerais, da propriedade que os textos têm de ser cheios de fragmentos de outros textos, os quais podem estar explicitamente citados, ou mesmo mesclados, fragmentos estes que o documento pode assimilar ou mesmo contradizer. $\mathrm{O}$ autor faz uma distinção entre intertextualidade manifesta, em que o texto recorre explicitamente a outro texto, e intertextualidade constitutiva, que é a configuração de convenções discursivas que entram em sua produção. De acordo com Fairclough (2001, p.134-135), o conceito aponta para a produtividade dos textos, isto é, como dados documentos podem transformar textos anteriores, reestruturar as convenções vigentes, e, assim, criar novos textos e novos sentidos.

Atentar-se para a intertextualidade é um expediente interessante para análise devido, sobretudo, à diferença entre os documentos: enquanto as NSS.02 e NSS.06 construíram sentidos mediante uma determinada caracterização atribuída aos EUA, terrorismo, Estados Párias e Falidos, e influenciaram a realidade a partir do momento em que foram capazes de produzir a crença na população de que o perigo do terrorismo nos termos ali propostos era real, a FSS.05 reproduz a relação apresentada nas NSS.02 e NSS.06, mas procura justificá-la mediante estudos que comprovem cientificamente tal relação. A intertextualidade ilumina, portanto, a importância de se mapear os momentos em que o documento busca subsídios em outras fontes para justificar seus argumentos e,

\footnotetext{
13 Jackson (2005) e Hodges (2011) mostram que para o êxito da Guerra ao Terror inscrever sentidos após os atentados, foi necessário a reprodução das ideias oferecidas pelo governo mediante segmentos distintos da sociedade, tais como mídia, academia e grupos religiosos. Sem a participação e adesão dessas parcelas, dificilmente a narrativa criada após os atentados teria conseguido se estabelecer.
} 
GOMES, A. T.; REIS, R. R.; ESPÍNDOLA, T. Terrorismo e Estados Falidos:...

assim, apresentar-se como comprovação das afirmações apresentadas nas NSS-02 e NSS-06. Notem-se os seguintes exemplos:

"Events of the last few years have tragically brought home the reality that situations unfolding on the other side of the world - governments collapsing, criminal and terrorist networks, humanitarian crises, and grinding poverty - can have global ramifications. Weak states tend to be the vector for these destabilizing forces, manifesting the dark side of globalization, and pose a very difficult kind of national security challenge. In countries that lack the ability, or will, to provide basic services or protection, we can no longer choose to look the other way. We need to engage gage in a coordinated and strategic manner to address the core issues of poverty and underdevelopment" (Fss-05, p. v, grifos nossos).

"The strategy identifies the ways that fragile states differ from those that are stable and able to pursue long.term development. It also identifies strategic priorities for fragile states and initial directions for USAID programming. Finally, the strategy focuses on management and administrative changes needed and outlines a new business model for USAID's operations in fragile states" (Fss-05, p. 2, grifos nossos).

"Research indicates that the instability associated with fragile states is the product of ineffective and illegitimate governance. Effectiveness refers to the capability of the government to work with society to assure the provision of order and public goods and services. Legitimacy refers to the perception by important segments of society that the government is exercising state power in ways that are reasonably fair and in the interests of the nation as a whole" (Fss-05, p. 3, grifos nossos).

O primeiro fragmento do documento retoma um tema caro às NSS.02 e NSS.06: os atentados de 11 de setembro desvelaram uma nova realidade, na qual o perigo vem de fora das fronteiras dos EUA e jaz, sobretudo, na incapacidade ou relutância de países vistos como fragilizados para se reformarem e acabarem com a pobreza endêmica e o subdesenvolvimento, o que os acaba tornando reféns de grupos terroristas. Temos nesse trecho um exemplo de intertextualidade manifesta, na medida em que a estratégia da USAID tem como seu ponto de partida os temas apresentados nos documentos anteriores. É inequívoca a associação entre Estados Falidos e terrorismo e, portanto, a agência deve contribuir para a compreensão e a resolução de tamanho problema.

O segundo trecho, por sua vez, ao indicar as intenções da estratégia pensada pela USAID e ao apresentar as ações necessárias para a erradicação do problema, é um bom exemplo de como o documento começa a agregar outros elementos para a construção de sentidos, especialmente ao introduzir uma solução técnica para a questão, tanto para o problema dos Estados Falidos, quanto para o próprio engajamento da agência nessas situações. De um lado, é necessário um engajamento técnico em países fragilizados, que os capacite a buscar desenvolvimento de longo prazo; por outro lado, temos a necessidade de uma mudança na forma como os EUA estruturam suas ações de ajuda externa, e aponta a necessidade de mudanças de ordem administrativa e novos modelos de gestão para a atuação da USAID.

O último trecho, por sua vez, apresenta as justificativas para tal prescrição e, para tanto, temos mais um movimento de intertextualidade manifesta: quem afiança a instabilidade dos países em tela não 
é o presidente, tampouco a USAID, mas sim pesquisas anteriores, as quais já haviam apreendido a associação entre Estados Falidos e terrorismo. Dito de outra forma, temos um quadro analítico previamente construído que justificaria a definição e as ações ora avançadas e que indicaria melhores rumos para a agência. Uma identificação científica e imparcial do problema e das soluções, e longe de ser atravessada por interesses políticos.

A pesquisa em questão é o artigo A Strategy Framework for the Assessment and Treatment of Fragile States, resultado do trabalho de Jack Goldstone, da George Mason University, e sua equipe de colaboradores do Center for Institutional Reform, da University of Maryland e citado como nota de rodapé na FSS-05. Dentre as principais ideias desenvolvidas por Goldstone et al (2004), três são mais salientadas na FSS.05: primeiro, a força ou fragilidade dos Estados advém primariamente das instituições dos países, principalmente aquelas relativas às dimensões política, social, econômica e de segurança; segundo, a qualidade da capacidade dos Estados depende da efetividade e da legitimidade das instituições de cada dimensão; e, terceiro, os problemas institucionais são causados na maioria das vezes pelo descompasso entre as condições políticas internas e as instituições e intervenções por meio das quais o país procura alcançar seus objetivos. Assim sendo:

\footnotetext{
"The most general principle distilled is that fragile states are those where the effectiveness and legitimacy of the institutions of state capacity (political, economic, social and security) do not, when taken together, create the necessary ability to manage internal conflicts, and ultimately the propensity for violence, or sufficient neutral ground. A specific imbalance of political power and objectives between contending groups - a governance gap, if you will . is usually at the heart of this fragility" (GOLDSTONE et al, 2004, p. xi).
}

Por conseguinte, as prioridades da USAID para Estados Falidos centram-se em quatro pilares, quais sejam, reforçar a estabilidade ao tratar das causas do conflito nas dimensões política, econômica e social, aumentar a segurança ao prover um ambiente que garanta a segurança pessoal, encorajar reformas, principalmente aquelas relacionadas com as condições que hoje estariam causando o fracasso, e, finalmente, desenvolver a capacidade das instituições consideradas fundamentais para a recuperação e o desenvolvimento do país. A tradução prática dessas diretrizes são opções como entrega de assistência humanitária e estabelecer a segurança quando os países estiverem em conflito, assim como apoiar a realização de eleições, auxiliar a construção de uma mídia independente, prover infraestrutura e serviços básicos, entre outras tarefas, após o fim dos conflitos internos.

Todavia, prioridades e tarefas não são opções deliberadas da agência: são indicações de outro estudo, organizado por Orr (2004). Este volume parte do pressuposto de que os EUA têm competência reconhecida para vencer guerras, mas, infelizmente, não sabem como estabelecer a paz em ambientes pós-conflito. Assim, a partir da ideia de que há quatro pilares principais para a construção da paz . segurança; governança e participação; bem-estar econômico e social; e justiça e reconciliação - Orr e colaboradores estabelecem ações práticas para ação, e a USAID faz uso dessas ideias para elaborar sua estratégia. Ou seja, da mesma forma que o diagnóstico é embasado em um estudo científico, a ação também o é. Novamente, reforça-se o caráter técnico e apolítico da questão. 
GOMES, A. T.; REIS, R. R.; ESPÍNDOLA, T. Terrorismo e Estados Falidos:...

Independentemente da grande controvérsia envolvendo avaliações institucionais sobre o fracasso estatal e as causas do terrorismo ${ }^{14}$, o fato é que a concepção ora apresentada influenciou mudanças na estrutura do governo norte-americano. De acordo com dados coligidos por Lancaster (2008), com o final da Guerra Fria e durante toda a década de 1990 a ajuda externa perdeu centralidade para os EUA, o que acarretou em uma depreciação de seu papel como elemento de política externa, assim como também redundou na diminuição do montante financeiro prometido para esta seara. Contudo, tal tendência foi revertida durante a administração George W. Bush: além de destacar o papel da ajuda externa nas duas estratégias de segurança nacional, em seu governo o montante destinado foi o maior desde o Plano Marshall, ultrapassando 25 bilhões de dólares no ano fiscal de 2005, já deduzidos os valores direcionados para as reconstruções do Iraque e Afeganistão e a ajuda militar ao Paquistão.

Além do acréscimo no volume, institucionalmente tivemos mudanças na maneira como a ajuda é dispensada, destacando-se a integração do planejamento e do orçamento da USAID junto ao Departamento de Estado, além do aumento do papel do Departamento de Defesa como provedor de assistência econômica. Na mesma toada, o governo elaborou o Millennium Challenge Account, programa anunciado em março de 2002, cuja ideia era aumentar em 50\% até o ano fiscal de 2006 o volume total da ajuda externa norte-americana para países em desenvolvimento que mostrassem avanços em indicadores relativos ao aumento das liberdades civis, direitos políticos, controle da corrupção, dentre outros. Uma ajuda condicionada, pensada como forma de se incentivar a promoção de democracias e reformas no âmbito político, econômico e em áreas afins de países considerados fracos. Ademais, com o fito de dinamizar e tornar mais bem-sucedido o envio de tropas e de recursos, o governo George W. Bush criou o Office of the Coordinator for Reconstruction and Stabilization, organismo inserido dentro do Departamento de Estado, responsável por coordenar os esforços de reconstrução e estabilização de países saídos de conflitos armados.

A despeito das críticas à forma como os EUA fazem uso da ajuda externa ${ }^{15}$, as reestruturações listadas podem ser consideradas reverberações importantes da associação estabelecida entre Estados Falidos e terrorismo, dado que criaram as condições para transformações na maneira como a política de ajuda externa do país é planejada, efetuada e, não menos importante, justificada perante o mundo.

\section{Prática Social}

Conforme mencionado inicialmente, à análise da prática social interessa averiguar como o discurso contribui para a transformação ou manutenção de determinado status quo. Para tanto, pretendemos compreender como a associação entre terrorismo e Estados Falidos insere-se nos interesses mais amplos dos EUA e, consequentemente, de que maneira contribui para justificar as ações externas do país após o 11 de setembro de 2001. Em nosso entender, é importante contextualizar

\footnotetext{
14 Uma leva de trabalhos questiona a associação entre Estados Falidos e terrorismo. Por exemplo, Hehir (2007), ao cruzar os dados da lista de Organizações Terroristas Internacionais, que, segundo o Departamento de Estado dos EUA, enumera os principais grupos em atividade, com o Failed States Index, argumenta que a intersecção em tela não oferece subsídios robustos para a associação entre Estados Falidos e terrorismo e que a presença de grupos terroristas é maior em países que não são considerados falidos, inclusive alguns deles democráticos. Para uma revisão de parte da literatura crítica à associação Estados Falidos e terrorismo, sugerimos Gomes (2011).

15 Patrick e Brown (2007) argumentam que, a despeito dos acréscimos financeiros e das mudanças estruturais, a política de ajuda externa dos EUA ainda é problemática. Ao desagregar o montante total destinado para ajuda externa, os autores afirmam que, excluindo-se Iraque, Afeganistão e Paquistão, os países que mais recebem auxílio financeiro dos EUA são Egito, Israel, Colômbia e Jordânia, países que não estão dentre aqueles considerados falidos. Ademais, os autores ainda criticam a postura reativa da política de ajuda norte-americana para Estados Falidos, salientando que a prevenção ainda é fraca e a coordenação entre as agências é caótica. Inobstante as críticas válidas, nosso ponto é que, ainda que questionemos a qualidade das mudanças, o fato é que as mesmas ocorreram e estão relacionadas à conexão entre Estados Falidos e terrorismo.
} 
brevemente a importância da democracia para a política externa do país após a Guerra Fria, assim como os impactos do que se convencionou chamar pensamento neoconservador, que teve influência significativa durante o governo de George W. Bush.

Assim sendo, ao final da Guerra Fria, analistas e policymakers debatiam qual seria o papel dos EUA em um sistema internacional não mais bipolar. Se outrora a fonte de legitimidade da ação internacional norte-americana era a contenção da URSS, nesse novo contexto, num mundo ainda sem a identificação de novos competidores, qual deveria ser a estratégia dos EUA? É dentro dessa conjuntura que ganha destaque a discussão sobre a promoção democrática como um dos pilares da política externa dos EUA para o pós-Guerra Fria. Cada qual a seu modo, as administrações norte-americanas destacaram a importância da democracia para a paz e segurança internacional, e como o país contribuiria para tal fim. Ao analisar 94 discursos presidenciais e 321 pronunciamentos de secretários de Estado norte. americanos, Castro Santos (2010) identifica três princípios relativos à democracia e qual o papel dos EUA no mundo pós-Guerra Fria: primeiro, os valores e princípios da democracia liberal ocidental são universais e, portanto, sua promoção é um bem para a humanidade; segundo, as democracias não lutam entre si e, consequentemente, promover a democracia é promover a paz mundial; terceiro, a promoção democrática faz o mundo mais seguro e próspero para os EUA. Logo, a missão dos EUA no mundo pós. Guerra Fria seria promover a democracia para os demais países do globo ${ }^{16}$.

Após o 11 de setembro, a importância do componente democrático na política externa do país ganhou destaque, sobretudo, devido à influência do pensamento neoconservador, cujos expoentes na administração George W. Bush eram pessoas como Paul Wolfowitz, secretário adjunto de defesa e o então vice-presidente Dick Cheney. De acordo com Teixera (2007), essa corrente de pensamento dá grande ênfase ao papel da democracia na política externa do país, destacando, dentre outros pontos, a ideia de que a promoção democrática é um imperativo moral, pois, recuperando ideias presentes desde a Independência dos EUA, acreditam que a liberdade individual é um absoluto moral, e a democracia seria, portanto, o regime político superior, na medida em que resguardaria tal liberdade, mas que não impediria atos como espionagem e violação de direitos civis básicos quando interesses políticos e econômicos estão em jogo. Assim sendo, Kagan e Kristol, dois expoentes do neoconservadorismo norteamericano, defendem a remoralização da política externa dos EUA a partir da crença americana de que os princípios da Declaração de Independência não são apenas escolhas de uma cultura particular, mas verdades universais, duradouras e autoevidentes ${ }^{17}$.

Ademais, os neoconservadores comungam da conexão entre democracia e segurança, na medida em que países democráticos seriam mais amistosos e menos propensos à guerra. Promover a

\footnotetext{
16 O debate sobre promoção da democracia, comumente designado como tese da Paz Democrática, foi um tema igualmente importante no debate acadêmico de Relações Internacionais durante a década de 1990, principalmente a partir das obras de Russett (1994), Brown et al (1996) e Russett e O'Neal (2001). Grosso modo, o argumento é que democracias tendem a não lutar entre si devido a dois motivos principais. Primeiramente, segundo explicações com ênfase institucional, o sistema político democrático com seus pesos e contrapesos impede que as lideranças declarem guerra de forma unilateral. Por outro prisma, há ainda explicações normativas, que argumentam que em suas relações exteriores democracias tendem a externar normas de convivência e tolerância para com os demais países do sistema internacional. Em boa medida, é possível afirmar que, se não explicitamente ao menos implicitamente, tais ideias serviram como justificativa para a ênfase na promoção democrática por parte da política externa norte-americana.

17 É conveniente ressaltar que o grupo neoconservador já teve presença anterior no governo, com destaque para a administração de George H. Bush (1989-1993), mas suas ideias não conseguiram aderência devido, sobretudo, ao contexto doméstico dos EUA na época, porquanto a principal preocupação relacionava-se a questões econômicas. Somente após os atentados é que o grupo em questão teve a oportunidade para implementar seu programa político e ideológico. Daalder e Lindsay (2004) e Teixeira (2007) são boas referências sobre esta discussão.
} 
GOMES, A. T.; REIS, R. R.; ESPÍNDOLA, T. Terrorismo e Estados Falidos:...

democracia seria, assim, uma estratégia eficaz para a segurança dos EUA, dado que a maior parte dos países considerados párias internacionais seriam regimes ditatoriais. Nessa toada, esta constelação de ideias abre espaço para a concepção de mudança de regime (regime change), que, em linhas gerais, consiste na ideia de que os EUA devem fazer uso de todos os meios possíveis para pressionar a fomentar a proliferação de democracias liberais pelo mundo. À luz do que consideram ser exemplos paradigmáticos de mudança de regime, Alemanha e Japão pós-Segunda Guerra Mundial, o argumento é que os EUA devem incentivar a transformação de regimes não democráticos em democracias liberais, pois seria um poderoso elemento para a paz e segurança internacionais. Todavia, quando necessário, os meios para se efetuar as mudanças de regimes não devem restringir-se à ajuda externa, por exemplo; de acordo com o pensamento neoconservador, intervenções militares devem ser levadas em consideração quando necessário.

Vemos, portanto, que a associação entre terrorismo e Estados Falidos não é algo trivial: a ideia de que principal problema do mundo é o terrorismo, e que sua causa mais profunda é a ausência de regimes democrático-liberais, apresenta, no mínimo, afinidades com as ideias presentes no debate sobre democracia e política externa dos EUA após a Guerra Fria. Em nosso entender, a natureza técnica atribuída ao problema dos Estados Falidos seria uma maneira de diminuir as controvérsias em torno da questão, apresentando-a como a verdade científica sobre o problema do fracasso estatal, e dissociada de questões políticas. Face os fatos apresentados, a opção seria intervenções precisas, direcionadas para as instituições burocráticas com vistas a fortalecer tais países.

Para ilustrar como tal associação contribui para justificar a ação internacional dos EUA, ao analisar a estratégia norte-americana para a África, Nasser (2009) chama a atenção para o fato de think tanks influentes no governo, como o Council on Foreign Relations, destacarem a necessidade de se ampliar o papel das forças militares do país e vigiar as fontes energéticas e os sistemas de distribuição do continente africano frente a vazios de poder e ameaças como o terrorismo, características do fracasso estatal. Com vistas a também ilustrar o ponto, é importante ressaltar que, no que tange aos interesses do capital privado, a empresa Halliburton, cujo um dos CEO foi o ex-vice-presidente Dick Cheney, arrecadou volumosos 39,5 bilhões de dólares desde o início da reconstrução do Iraque em 2003, mediante contratos com o governo iraquiano e com o governo norte-americano, o que mostra como os sentidos construídos trabalharam em favor da manutenção de um determinado status quo e de interesses econômicos de uma elite com ligações íntimas com o governo ${ }^{18}$.

Ademais, ainda sobre o caso do Iraque, Chapaux (2009) afirma que a então administração republicana, ainda que não tenha dito que o país era um Estado Falido quando do início da invasão, mobilizou o conceito para justificar e legitimar a presenças das tropas, visto que "os Estados que estão no Iraque têm que ficar para evitar a produção de um novo Estado Falido" (POWELL, 2003, apud CHAPAUX, 2009, p. 122). Para além, Raphael (2009) argumenta que boa parte das análises sobre terrorismo publicadas em periódicos como Terrorism and Political Violence e Studies in Conflict and Terrorism

\footnotetext{
18 Tais dados podem ser encontrados em: <http://readersupportednews.org/news-section2/308-12/16561-focus-cheneys halliburton-made-395-billion-on-iraq-war> e <http://leaksource.wordpress.com/2013/04/08/contractors-reap-138-billion-from iraq-war-cheneys-halliburton-1-with-39-5-billion/>. Acesso em: 24 nov. 2013.
} 
foram realizadas por pessoas com ligação com o governo, provendo justificação intelectual para as controversas práticas de contraterrorismo e para as políticas de segurança ${ }^{19}$.

Assim sendo, à luz da contextualização apresentada, podemos compreender e situar a emergência da associação entre terrorismo e Estados Falidos: o debate sobre as causas do terrorismo está relacionado com a importância que os EUA destacam para a promoção democrática como variável para garantir a paz e a segurança internacional desde o final da Guerra Fria, e, por conseguinte, ao estabelecer a importância da democracia como solução para o fracasso estatal teríamos um reforço importante para a visão dos EUA sobre o problema do terrorismo transnacional, além de um expediente bastante conveniente para intervenções, as quais passam a possuir um caráter técnico. Ademais, temos também uma nova maneira de se continuar destacando a importância de se promover democracias pelo mundo e, assim, justificar e legitimar a presença norte-americana no mundo.

Somados os pontos, a construção de sentidos apresentada nos documentos e reforçada pelas práticas da política externa norte-americana não é nada arbitrária, mas sim contribui para justificar e legitimar a ação externa do país após os atentados de 11 de setembro de 2001, porém apresentando continuidades significativas com a discussão ideológica e política presente desde o final da Guerra Fria nos EUA. Nesse sentido, termos como Estados Falidos e Mudança de Regime podem, à primeira vista, parecer novidade no léxico político dos EUA, mas quando analisados a partir dos insights da Análise de Discurso Crítica, notamos que os mesmos estão intimamente conectados aos interesses políticos e econômicos de longo prazo dos EUA que, no mínimo, remontam ao final da Guerra Fria. Nota-se, portanto, que as interpretações desenvolvidas sobre a política externa dos EUA são resultado de uma análise conjunta das três etapas sugeridas por Fairclough, evidenciando, salvo melhor juízo, a importância de ponderações oriundas da Linguística para discussões da área de Relações Internacionais.

\section{Considerações Finais}

Quando iniciamos o artigo, dissemos que almejávamos realizar uma dupla intervenção no debate. Primeiramente, com relação ao debate acadêmico, nossa contribuição passa por destacar a utilidade analítica da Análise de Discurso Crítica para a área de Relações Internacionais. Assim, mediante o aporte conceitual de Norman Fairclough, procuramos mostrar que a associação entre terrorismo e Estados Falidos como um problema de natureza técnica construída nos documentos selecionados e propagados pela administração republicana produziu impactos na estrutura administrativa do país, além de ser um expediente conveniente para intervenções militares, mas não pode ser dissociada dos interesses políticos e ideológicos dos EUA desde o final da Guerra Fria, contribuindo assim para justificar e legitimar a ação externa do país após os atentados de 11 de setembro. Esperamos que a relação dialética entre discurso e realidade, tal como formulado por Fairclough, tenha sido exemplificada pela análise aqui realizada e que, assim, possamos fomentar a utilidade analítica da Análise de Discurso Crítica e estreitar as possibilidades de diálogo com a área de Relações Internacionais, dado que temas como intervenções humanitárias, operações de paz e direitos humanos, por exemplo, mostram-se ricos para investigações informadas pelo prisma discursivo.

\footnotetext{
19 Raphael (2009) aponta que os principais experts em terrorismo nos EUA, tais como Martha Crenshaw, Bruce Hoffman e Walter Laqueur, por exemplo, passaram por órgãos como a CIA e o Departamento de Estado, e que as análises realizadas e publicadas nos periódicos entre o período de 1974 e 2004 tendem a replicar as análises do governo norte-americano sobre o assunto.
} 
GOMES, A. T.; REIS, R. R.; ESPÍNDOLA, T. Terrorismo e Estados Falidos:...

Com relação à intervenção no debate político, esperamos ter mostrado que a construção da associação entre terrorismo e Estados Falidos, a despeito de seu caráter técnico, foi influenciada por discussões políticas e ideológicas. Assim, trata-se de problematizar uma construção de sentidos que hodiernamente é tratada de como isenta de interesses e que informa a ação política não apenas dos EUA, mas também de organizações internacionais e de outros países. Ao destacar a produção do discurso como prática social e a forma como ele influencia e é ao mesmo tempo influenciado por outras práticas, esperamos ter contribuído para questionar a visão técnica sobre o fracasso estatal, o que, salvo melhor juízo, está longe de ser a melhor resposta para a discussão acerca das causas do terrorismo transnacional e dos países considerados fracassados.

\section{Referências Bibliográficas}

Berber Sardinha, T. Linguística de Corpus. Barueri: Manole, 2004.

BRown, M.; Lynn-Jones, S.; MILleR, S. (org.). Debating the Democratic Peace. Cambridge: MIT Press, 1996.

BuSH, G. W. The National Security Strategy of the United States of America. White House: Washington D.C, 2002.

National Strategy for Combating Terrorism. White House: Washington D.C., 2003.

CASTRO SAntos, M. H. “Exportação da democracia na política externa norte-americana: doutrina e uso da força”. Revista Brasileira de Política Internacional, Brasília, vol. 53, n¹, p.157-191, 2010.

Chapaux, V. "Imposición de un Modelo Universal del Estado Exitoso? Estudio de la noción de Estado Fallido". Cuadernos sobre Relaciones Internacionales, Regionalismo y Dessarollo, Mérida, vol. 4, n 7, p.117.144, 2009.

Chouliaraki, L.; Fairclough, N. Discourse in Late Modernity. Edinburgh: Edinburgh University Press, 1999.

DAALDER, I.; LINDSAY, J. America Unbound: the Bush revolution in foreign policy. New Jersey: John Wiley and Sons, Inc., 2004.

FaIRCLough, N. Discurso e Mudança Social. Brasília: Editora UnB, 2001.

Analysing Discourse: textual analysis for social research. London: Routledge, 2003

Foucault, M. Sobre a Arqueologia das Ciências. Resposta ao Círculo da Epistemologia. In: Foucault, M. Ditos e Escritos II: Arqueologia das Ciências e História dos Sistemas de Pensamento. Rio de Janeiro: Forense Universitária, 2008.

Goldstone, J.; HAUGhton, J.; SoltAn, K.; ZINNES, C. A Strategy Framework for the Assessment and Treatment of Fragile States. Washington: PPC IDEAS, 2004.

Gomes, A.T. "Questionando o fracasso estatal: um balanço da literatura crítica". BIB: Revista Brasileira de Informação Bibliográfica em Ciências Sociais, São Paulo, n71, p.69-94, 2011.

"O Colapso e a Reconstrução: uma análise do discurso sobre Estados Falidos e Reconstrução de Estados". São Paulo. 249 p. Tese (Doutorado). USP, 2012.

HeHIR, A. "The Myth of the Failed State and the War on Terror: a challenge to conventional wisdom". Journal of Intervention and Peacebuilding, Londres, vol.1, n³, p.307.333, 2007.

Hodges, A. The War on Terror Narrative: Discourse and Intertextuality in the Construction and Contestation of Sociopolitical Reality. New York: OUP, 2011.

JACKSON, R. Writing the War on Terrorism: language, politics and counter-terrorism. Manchester: Manchester University Press, 2005.

JARVIS, L. Times of Terror: discourse, temporality and the War on Terror. New York: Palgrave, 2009.

LANCASTER, C. George Bush's Foreign Aid: Transformation or Chaos? Washington D.C: Brookings Institution Press, 2008.

LITWAK, R. Rogue States and U.S. Foreign Policy: Containment after the Cold War. Washington D.C: Woodrow Wilson Center Press, 2000. 


\section{OPINIÃO PÚBLICA, Campinas, vol. 20, no 2, agosto, 2014, p. 291-310}

Regime Change: U.S strategy through the prism of 9/11. Washington D.C: Woodrow Wilson Center Press, 2007.

LYNN-Doty, R. "Foreign Policy as Social Construction: a Post-Positivist analysis of U.S. Counterinsurgency Policy in Philippines". International Studies Quarterly, Chichester, vol.37, p.297-320, 1993.

MAgalhães, I. "Introdução: a Análise de Discurso Crítica”. D.E.L.T.A., São Paulo, 21, p.1-9, 2005.

Mendes, C. "A Construção do conceito de Terrorismo: análise dos discursos do ex - Primeiro Ministro britânico Tony Blair". Brasília. 233 p.Tese (Doutorado). Universidade de Brasília, 2008.

MonteIRo, L. "O Conceito de Estado Fracassado nas Relações Internacionais: Origens, Definições e Implicações Teóricas". São Paulo. 152 p. Dissertação (Mestrado). Programa San Tiago Dantas de Relações Internacionais UNESP/UNICAMP/PUC.SP, 2006.

MONTEN, J. "The Roots of the Bush Doctrine: Power, Nationalism, and Democracy Promotion in U.S Strategy". International Security, Boston, vol. 29, n 4, p.112-156, 2005.

NABERS, D. "Filling the Void of Meaning: Identity Construction in U.S. Foreign Policy after September, 11, 2001". Foreign Policy Analysis, Chichester, vol. 5, p.191.214, 2009.

NASSER, R. Os Estados Falidos: Novas Ameaças e Novas Oportunidades. In: NASSER, R. (org.). Os Conflitos Internacionais em suas Múltiplas Dimensões. São Paulo: Editora Unesp, 2009.

ORR, R. Winning the Peace: an American Strategy for Post-Conflict Reconstruction. Washington D.C.: Center for Strategic and International Studies, 2004

PATRICK, S.; BRown, K. Greater than the sum of its parts? Assessing "Whole of Government" Approaches to Fragile States. New York: International Peace Academy, 2007.

PILLAR, P. Terrorism and U.S. Foreign Policy. Washington D.C.: Brookings Institution Press, 2003.

Rajagopalan, K. Por uma Linguística Crítica. São Paulo: Parábola, 2003.

Ramalho, V. "O discurso da imprensa brasileira sobre a invasão anglo-saxônica ao Iraque". Brasília. 194 p. Dissertação (Mestrado). UnB, 2005.

RAPHAEL, S. In the service of power: terrorism studies and US intervention in the Global South. In: JACKSON, R.; BREEN, M.; GUNNING, J. (org.). Critical Terrorism Studies: a new research agenda. New York: Routledge, 2009.

Resende, E. Americanidade, Puritanismo e Política Externa. Rio de Janeiro: Contra Capa, 2012

RESENDE, V. "Literatura de cordel no contexto do novo capitalismo: o discurso sobre a infância nas ruas". Brasília. 258 p. Dissertação (Mestrado). UnB, 2005.

Ramalho, V. Análise de Discurso Crítica. São Paulo: Editora Contexto, 2006.

RUSSET, B. Grasping the Democratic Peace. Princeton: Princeton University Press, 1994.

RUSSET, B.; O'NEAL, J. Triangulating Peace: Democracy, Interdependence, and International Organizations. New York: W.W.Norton \& Company, 2001.

Santo NetTo, M. "O Troféu da Anarquia: Simon Bolívar, guerras de independência, e a formação discursiva do nacionalismo hispano-americano (1810-1820)". Belo Horizonte. 95 p. Dissertação (Mestrado). PUC.Minas, 2011.

TeIXEIRA, C. "O Pensamento Neoconservador em Política Externa nos EUA”. São Paulo. 128 p. Dissertação (Mestrado). Programa San Tiago Dantas de Relações Internacionais UNESP/UNICAMP/PUC.SP, 2007.

VILELA, E.; NeIVA, P. "Temas e Regiões nas políticas externas de Lula e Fernando Henrique: comparação do discurso dos dois presidentes". Revista Brasileira de Política Internacional, Brasília, vol. 54, n², p. 70.96, 2011.

USAID. Fragile States Strategy. Bureau for Policy and Program Coordination, USAID: Washington D.C, 2005.

WODAK, R. What CDA is about - a summary of its history, important concepts and its development. In: WODAK, R.; MEYERS, M. Methods of Critical Discourse Analysis. London: Sage Publications, 2001.

Aureo de Toledo Gomes · aureo@ie.ufu.br Rossana Rocha Reis·rossanarr@usp.br Tainah Espíndola·tainahespindola@yahoo.com.br

Submetido à publicação em março de 2013. Versão final aprovada em janeiro de 2014. 